\title{
BMJ Open Psychological distress during COVID-19 pandemic in low-income and middle- income countries: a cross-sectional study of older persons in Thailand
}

Wiraporn Pothisiri, Paolo Miguel Manalang Vicerra

To cite: Pothisiri W, Vicerra PMM. Psychological distress during COVID-19 pandemic in low-income and middle-income countries: a cross-sectional study of older persons in Thailand. BMJ Open 2021;11:e047650. doi:10.1136/ bmjopen-2020-047650

- Prepublication history for this paper is available online. To view these files, please visit the journal online (http://dx.doi. org/10.1136/bmjopen-2020047650).

Received 07 December 2020 Revised 16 February 2021 Accepted 15 April 2021

Check for updates

(C) Author(s) (or their employer(s)) 2021. Re-use permitted under CC BY-NC. No commercial re-use. See rights and permissions. Published by BMJ.

College of Population Studies, Chulalongkorn University, Bangkok, Thailand

Correspondence to Dr Paolo Miguel Manalang

Vicerra;

pmvicerra@alum.up.edu.ph

\section{ABSTRACT}

Objective The COVID-19 situation in Thailand was controlled with various social measures. Much of the information covered in the media and in studies focused on the public health and economic aspects of the pandemic. This study aimed to explore the psychological well-being of older people, which is important especially in an ageing society categorised as low income or middle income due to the limits of economic and healthcare resources.

Setting The impact of COVID-19 on older persons in Thailand, an online survey, taken across nine provinces within the five regions of the country.

Participants Information was collected from 1230 adults aged at least 60 years old.

If an older person was illiterate, unable to access the internet or had a disability preventing them from responding to the survey, an intermediary residing in the community conducted the survey interview.

Primary and secondary outcome measures The analysis focused on the worries of older adults and the factors associated with psychological distress experienced during the pandemic using logistic regression analysis. Results The majority of people aged at least 60 years old experienced psychological distress during COVID-19. Employment loss (OR 1.08, 95\% $\mathrm{Cl} 0.78$ to 1.38 ), inadequate income (OR $1.77,95 \% \mathrm{Cl} 1.28$ to 2.44 ) and debt incursion (OR $2.74,95 \% \mathrm{Cl} 1.57$ to 4.80 ) were detrimental to psychological well-being. The negative changes in the perception of their health status (OR 1.92, $95 \% \mathrm{Cl} 1.23$ to 2.99 ) and decreased life satisfaction (OR $1.49,95 \% \mathrm{Cl} 0.45$ to 1.87 ) also weighed on older Thais. The protective factors for psychological well-being were residing in rural areas $(0 \mathrm{R} 0.46,95 \% \mathrm{Cl} 0.35$ to 0.61$)$ and being married (OR $0.75,95 \% \mathrm{Cl} 0.55$ to 1.01 ).

Conclusion Observing the concerns of the older population is important for introducing policies that can alleviate their precarious financial and health statuses.

\section{INTRODUCTION}

The COVID-19 was declared a public health emergency by WHO on 30 January $2020 .{ }^{1}$ The contexts of each society vary, and this signals differences in response with regard to measures to curb the spread of the virus. The measures relating to restrictions on mobility
Strengths and limitations of this study

This study adds evidence on the psychological effect of COVID-19 pandemic in older adults.

- The theme of the psychological well-being of older adults is often overlooked, especially during health emergencies in the context of low-income and middle-income countries.

- This study offers insights into the effect of the pandemic on the resources of older adults who need to continue working despite the situation.

- Self-reported health status was the main measure used in this study, and therefore, causation cannot be established.

and economic activity had immediate psychological health impacts on populations of different countries, including Belgium, Canada and France. ${ }^{2}$ Although entire populations were affected negatively by the situation, the effects were greater among the older population aged 60 years or older in terms of anxiety and depressive risks. ${ }^{34}$

Physically distancing through sheltering in place was identified as among the factors associated with higher reports of anxiety and depression at the community level across several countries. ${ }^{56}$ This unexpected circumstance required sudden lifestyle adjustments which are difficult to manage especially among older adults. It is important to note these changes, because the psychological wellbeing of older persons is related to comorbidities that increase mortality risks. ${ }^{37}$ Notably, the impacts of the pandemic are heterogeneous across societies. The effects of the pandemic with regard to the health and well-being of populations in low-income and middle-income countries remain uncertain due to differences in resources and the status of vulnerable populations. ${ }^{89}$

In Thailand, the first positive case was identified on 12 January 2020. From that point 
on, the government monitored the situation, and on 22 March, they enacted lockdown measures. This restricted the mobility of the population in their communities and the activities of businesses. The public health situation gravely affected life in the country, especially for those of advanced age. Thailand is an ageing society in which $19 \%$ of the total population is at least 60 years old. ${ }^{10}$ The comorbidities of COVID-19 that increase risks of mortality are prevalent, as non-communicable diseases, such as diabetes and obesity, appeared to have been increasing in recent decades. ${ }^{11}$ Despite this context, life expectancy had been increasing over the years, ${ }^{12}$ and a substantial proportion of older people remained engaged in economic activities. ${ }^{13}$ The pandemic has affected the need for continued gainful employment among adults, and this extends to the older population, further exacerbating the situation.

This study focuses on the psychological well-being of the older population of Thailand during the COVID-19 pandemic. Studies have been done regarding other aspects of health, such as the adoption of preventive behaviours in older people ${ }^{14}$ and the level of physical activity among both young and older adults. ${ }^{15}$ The protection of public health and safety is of primary importance especially during public health emergencies, but psychological health and well-being also need attention. One study examined anxiety experienced due to COVID-19, but it concerned only the general population of Bangkok. ${ }^{16}$ The psychological distress of older people across the regions of Thailand has yet to be explored.

\section{METHODS \\ Data}

This study used the data from the Impact of COVID-19 on Older Persons in Thailand survey conducted in July 2020 by the College of Population Studies, Chulalongkorn University. ${ }^{17}$ This survey was the first to specifically focus on the impacts of social policies and actions during the COVID-19 pandemic on the older population in the country. The aim was to gather information on the population aged 60 years old and older regarding their socioeconomic status, living arrangement, physical and psychological health, and daily activities before and during the COVID-19 outbreak. The survey questionnaire was reviewed by national and international experts. Funding for the survey was provided by the Thailand Country Office of the United Nations Population Fund.

Data were collected in July 2020 when national lockdown measures had mostly been relaxed, but avoidance of face-to-face interactions was still recommended by governmental agencies; therefore, an online survey method was deemed appropriate. The survey employed a multistage, proportionate-to-size probability design with geographic and administrative stratification. The sample consisted of 1230 respondents aged 60 and over living 11 urban communities and 7 rural villages in nine provinces across five regions of the country including Bangkok. A local resident in the community acted as an intermediary for respondents who required assistance because they were illiterate, had no access to a smart phone or the internet, or had difficulty navigating the survey platform.

\section{Measures}

This study aimed to observe psychological well-being, using the experience of psychological distress as the measure, of older people in Thailand. It was based on the survey question, During the COVID-19 outbreak, how frequently did you experience the following symptoms or feelings?' The symptoms were loss of appetite, no hope in life, unhappy, sad and lonely. The response options for the question were never, sometimes and always. The responses 'sometimes' and 'always' were combined to become the outcome category for having psychological distress. The total score for the index was 5. From this, the dependent variable was transformed into a dichotomous category whereby the outcome category included those who had at least one symptom. The items used to create the index for psychological distress were tested and showed an appropriate level of reliability (Cronbach's alpha $=0.81$ ) .

Selected demographic factors were included in the analysis, namely age, gender, residence and marital status. Living arrangement was also included, where the categories were living alone, living with a spouse and children, if any, and living with other people including relatives, caretakers and other non-family members.

Several socioeconomic characteristics were also part of the analytic model. Educational attainment was categorised into three groups: those with lower than primary education ( $0-3$ years of education); people with a primary education (4-6 years) and individuals with higher than a primary education. Employment status was measured in reference to the period before COVID-19 began. Respondents were asked if they had worked in the 12 months before the outbreak began and if they continued to work during the COVID-19 period. Three categories were created, namely, no work before COVID-19, continued work during the situation, and loss of employment during the pandemic.

Average annual income information was also collected and categorised dichotomously into those who earned less than $B 30000$ and those who had earned at least $B 30$ 000 in the year before COVID-19. Debt status was considered similarly such that its reference point included the period before COVID-19, creating three categories: no debt, in debt before COVID-19, and incurred debt during the outbreak. Income adequacy was also incorporated into the study as the respondents were asked if their income during the pandemic was adequate or inadequate. The respondents were also asked if their spending was impacted during the outbreak. The expenditures included were food, water and electricity utilities; job expenses (eg, fuel costs); COVID-19-related costs for items such as face masks; medicine and medical supplies; and child/grandchild-related expenses (eg, online 
learning fees and living expenses during the school break). A dichotomous variable was created for impacted expenditure, where having at least one affected spending area would place the respondent in the unity category.

Socialisation disruptions and changes in health perception were also included in the analysis. Having at least one area of daily routine affected counted as a disrupted activity. The survey asked about four mobility activities: leaving the house to run errands, buy groceries, keep medical appointments and attend religious ceremonies. Socialisation activities included meeting with family and relatives, meeting friends, and participating in social activities. In terms of changes in health, respondents were asked if they had experienced changes in the following during the outbreak: vision, hearing, mobility, communication, memory and personal care. Having at least one change was classified as the outcome category in the variable. Finally, the survey asked older individuals if they had worse self-rated health and life satisfaction during the COVID-19 social restriction period.

\section{Statistical analysis}

The distribution of the sample's characteristics is presented in table 1 . The difference between the respondents who experienced psychological distress during the pandemic and those who did not was tested using a $\chi^{2}$ test. For the multivariate analysis, a bivariate logistic regression model analysis was used to determine the factors associated with psychological distress during COVID-19. This regression model is appropriate because the outcome was measured dichotomously to differentiate between the presence and absence of the experience of psychological distress. Multicollinearity was tested by estimating the variance inflation factor. The results show that there was minimal multicollinearity among the independent variables included in the analyses. All the analyses were performed using Stata V.13.1 (StataCorp).

\section{Patient and public involvement}

The present study used secondary data. Neither patients nor the public were directly involved in the design, conduct or reporting plans of the research.

\section{RESULTS}

About $57 \%$ of individuals in the sample experienced psychological distress during the COVID-19 pandemic (table 1). Respondents in urban areas reported more psychological distress than those in rural areas. A similar reporting of higher distress was found among those who lived alone and those with lower levels of education. A higher prevalence of psychological distress was further observed among those who had lost their employment during COVID-19 (66\%, 310 respondents), had inadequate income (68\%, 533 respondents), and incurred debt during the outbreak ( $81 \%, 87$ respondents). Those who experienced affected expenditures, disruptions in socialisation, and lower health and well-being statuses also suffered a higher prevalence of psychological distress.

The financial status of older people in Thailand was already vulnerable before the pandemic. Before March 2020, many older people in the sample cited that they were working as a means to generate their main income (figure 1). At a similar level (40\%), people were also receiving government subsidies, especially the old-age allowance. Some were receiving support from their families and fewer were under the pension system and had savings.

The main source of income among the respondents changed during the pandemic. Those who indicated they worked as means to generate income decreased by half, while those who received subsidies increased to $56 \%$.

Uncertainties compounded during the COVID-19 pandemic as shown in the list of concerns of older people (figure 2). Few had concerns with their living situation. More were fretful with regard to health and financial issues. Respondents were primarily concerned about themselves or their families becoming infected with the disease $(41 \%)$. Following this was concern about their financial situation (28\%).

In table 2, the associated factors were observed based on the logit model analysis. The oldest group (80 years and above) was observed to have a higher prevalence of psychological distress than those in the 60-69 years old age group. Living in a rural area, being married, having a higher level of education, being employed even during the pandemic, and having a higher level of income were observed to have a negative association with psychological distress.

The economic situation of older people was also observed to have an influence on their psychological symptoms. Employment loss was positively associated with the outcome $(\mathrm{OR}=1.1, \mathrm{p}=0.090)$. Similar observations were found for income inadequacy $(\mathrm{OR}=1.77$, $\mathrm{p}=0.001$ ) and having debt, whether it was incurred before COVID-19 (OR=1.48, $\mathrm{p}=0.015)$ or during the pandemic $(\mathrm{OR}=2.74, \mathrm{p}<0.001)$. Having at least one affected area of expenditure was also negatively associated with psychological distress. Perceived health and well-being changes had a negative association with the outcome, as observed with having worse health during COVID-19 (OR=2.01, $\mathrm{p}=0.003)$, experiencing health difficulties $(\mathrm{OR}=1.92$, $\mathrm{p}=0.004)$, and dissatisfaction with one's life situation during the pandemic $(\mathrm{OR}=1.49, \mathrm{p}=0.023)$.

\section{DISCUSSION}

Psychological well-being in older people is an important subject to study but is often overlooked in the literature, particularly in the context of developing economies. ${ }^{18}$ The context of the COVID-19 pandemic also brings to the forefront certain issues that the older population encounters in relation to social and economic factors. This study observed that socioeconomic factors, such as education and income levels, were associated with psychological 
Table 1 Sample distribution of individual characteristics by experience of psychological distress, Thai older persons aged 60 years and older, 2020

\begin{tabular}{|c|c|c|c|c|}
\hline \multirow[b]{2}{*}{ Variable } & \multirow[b]{2}{*}{ Total } & \multicolumn{2}{|c|}{$\begin{array}{l}\text { Experience of psychological } \\
\text { distress (\%) }\end{array}$} & \multirow[b]{2}{*}{ P value* } \\
\hline & & No & Yes & \\
\hline \multicolumn{5}{|l|}{ Age groups } \\
\hline $60-69$ & 707 & 42.57 & 57.43 & 0.947 \\
\hline $70-79$ & 376 & 43.62 & 56.38 & \\
\hline $80+$ & 147 & 42.86 & 57.14 & \\
\hline Female & 682 & 41.94 & 58.06 & 0.433 \\
\hline Rural area & 712 & 51.69 & 48.31 & $<0.001$ \\
\hline Married & 784 & 44.39 & 55.61 & 0.170 \\
\hline \multicolumn{5}{|l|}{ Living arrangement } \\
\hline Living alone & 68 & 38.24 & 61.76 & 0.722 \\
\hline Living with spouse and/or children & 1047 & 43.17 & 56.83 & \\
\hline Living with other people & 115 & 43.48 & 56.52 & \\
\hline \multicolumn{5}{|l|}{ Educational attainment } \\
\hline Lower than primary level (1-3 years) & 91 & 38.46 & 61.54 & 0.639 \\
\hline Primary level (4-6 years) & 845 & 43.55 & 56.45 & \\
\hline Higher than primary level & 294 & 42.52 & 57.48 & \\
\hline \multicolumn{5}{|l|}{ Employment status } \\
\hline None & 649 & 44.68 & 55.32 & $<0.001$ \\
\hline Working before and during COVID-19 & 109 & 69.72 & 30.28 & \\
\hline Loss of employment during COVID-19 & 472 & 34.32 & 65.68 & \\
\hline Higher average annual income (30000 Baht and more) & 530 & 49.25 & 50.75 & $<0.001$ \\
\hline Inadequate income & 784 & 32.02 & 67.98 & $<0.001$ \\
\hline \multicolumn{5}{|l|}{ Debt status } \\
\hline None & 773 & 49.81 & 50.19 & $<0.001$ \\
\hline Existing debt before COVID-19 & 350 & 35.14 & 64.86 & \\
\hline Incurred debt during COVID-19 & 107 & 18.69 & 81.31 & \\
\hline Spending capacity affected during COVID-19 & 871 & 35.48 & 64.52 & $<0.001$ \\
\hline Disrupted mobility activities & 939 & 39.51 & 60.49 & $<0.001$ \\
\hline Disrupted socialisation activities & 692 & 39.02 & 60.98 & 0.002 \\
\hline Worse self-rated health than before COVID-19 & 213 & 15.96 & 84.04 & $<0.001$ \\
\hline Experienced physical difficulty during COVID-19 & 171 & 21.05 & 78.95 & $<0.001$ \\
\hline Lower life satisfaction during COVID-19 & 321 & 26.79 & 73.21 & $<0.001$ \\
\hline Total & 1230 & 42.9 & 57.1 & \\
\hline
\end{tabular}

Source: Impact of COVID-19 on Older Persons in Thailand Survey.

${ }^{*}$ Based on the $\chi 2$ test

distress. The perception of income inadequacy and the pandemic's effect on debt and expenditures were also detrimental to the mental well-being of older people. Negative perceptions of one's health status were also observed to be negatively associated with psychological distress.

Concerns about financial status among older people and its negative effects on well-being were previously observed in a study in Sweden. ${ }^{19}$ As shown in the results of the current study, financial concerns have also been experienced by many older Thais. Uncertainties surround people because of the halting of various economic sectors during the lockdown measures to control the outbreak. The susceptibility of people in Thailand to market shocks has also been previously studied. ${ }^{20} \mathrm{~A}$ major contributing factor was that most adults, including older people, are engaged in the formal labour sector, especially in urban areas. ${ }^{21}$ As economic output declined due to the pandemic, a large portion of the population, regardless of age, lost their employment. This may have had an impact 


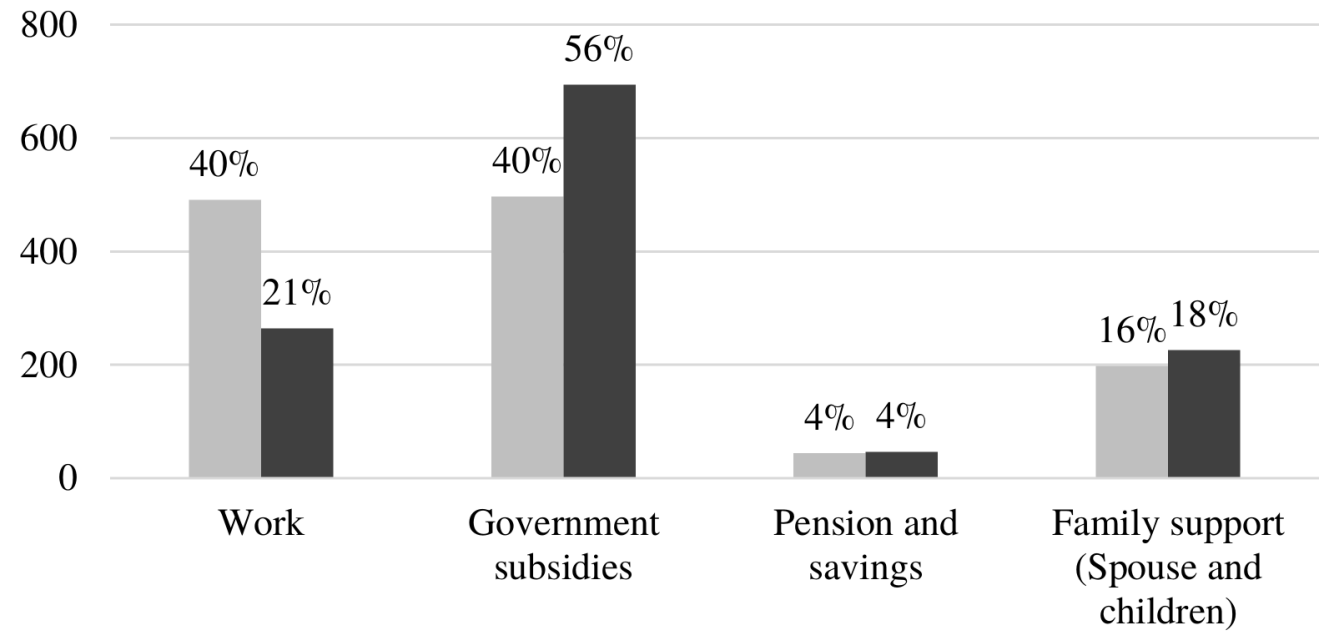

Before COVID-19 During COVID-19

Figure 1 Main sources of income of older Thais before and during COVID-19. Percentage distribution of wage sources among adults in the study sample. Source: Impact of COVID-19 on Older Persons in Thailand Survey.

on another source of income among older Thais, namely support from their families, particularly if they have children. ${ }^{22}$ Although many older people continued to receive support from their family members, the amount received may have been affected by the conspicuous loss of employment for all adults across the country.

Avenues to earn income were curtailed because of COVID-19. The employment trend of the 1990s to the 2000s, during which more than a third of the older population of Thailand was in the labour force, has been noted ${ }^{23}$ It is a necessity for some older Thais to participate in the labour force, as many worked in the informal sector during their younger years, leading to the lack of a pension. ${ }^{24}$ The loss of this source of income has a great effect on the financial capacity of older individuals and has thus caused concern.
As mentioned above, most older Thais lack a pension. The old age allowance system was established to provide social protection. ${ }^{24}$ This means-tested programme, established in 1993, developed into a universal social scheme whereby older persons with no pension account would receive a certain amount proportional to age: $\mathbf{B 6 0 0}$ (US\$19.9 as of this writing) per month for persons aged 60-69 years, $B 700$ (US\$23.2) for those 70-79 years old, B800 (US $\$ 26.5$ ) for those $80-89$ years old and $\$ 1000$ (US\$33.1) for those aged at least 90 years old. The amount received was prone to insufficiency, as it was fixed and did not respond to changing inflation rates or the current poverty threshold. ${ }^{25}$

A poorer perception of health status was also found to be negatively associated with psychological distress. Self-rated health, self-reported health manifestations,

Conflict with my family while living together

Living alone if any family member were to be infected with COVID-19

Unable to purcahse essentials (i.e food and medicine)

Accessibility to the treatment if infected with COVID-19

Health status worsens because of missed medical appointments

Personal and familial financial status

Getting myself or my family member infected with COVID-19

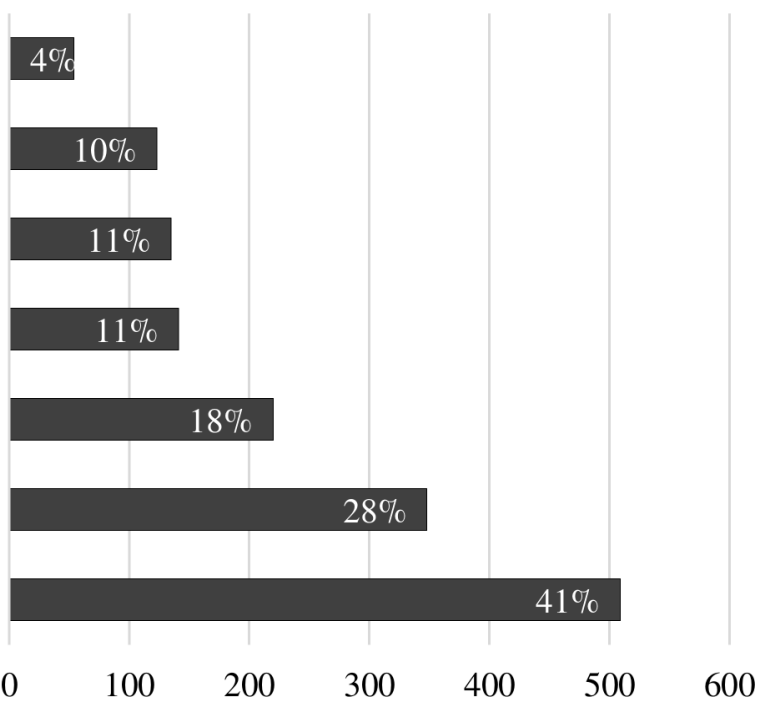

Figure 2 Areas of concern among survey respondents during COVID-19. Percentage distribution of sources of worries during lockdown period in Thailand among the respondents in the sample. Source: Impact of COVID-19 on Older Persons in Thailand Survey. 
Table 2 Logit regression model predicting the likelihood of experiencing psychological distress, Thai older persons aged 60 years and older, 2020

OR $95 \% \mathrm{Cl} \quad$ P value $^{*}$

\begin{tabular}{llll|}
\hline $\begin{array}{l}\text { Age groups } \\
60-69 \text { (Ref) }\end{array}$ & & & \\
$70-79$ & 1.16 & 0.85 to 1.58 & 0.308 \\
\hline $80+$ & 1.52 & 1.01 to 2.31 & 0.088 \\
\hline Female & 0.93 & 0.71 to 1.21 & 0.585 \\
\hline Rural residence & 0.46 & 0.35 to 0.61 & $<0.001$ \\
Married & 0.75 & 0.55 to 1.01 & 0.042 \\
\hline
\end{tabular}

Living arrangement

\section{Living alone (Ref)}

$\begin{array}{llll}\text { Living with spouse and/or } & 0.99 & 0.93 \text { to } 1.05 \quad 0.883\end{array}$ children

\begin{tabular}{|c|c|c|c|}
\hline Living with other people & 0.90 & 0.56 to 1.23 & 0.788 \\
\hline \multicolumn{4}{|l|}{ Educational attainment } \\
\hline \multicolumn{4}{|l|}{ Lower than primary level (Ref) } \\
\hline Primary level (4-6 years) & 0.79 & 0.47 to 1.11 & 0.431 \\
\hline Higher than primary level & 0.79 & 0.50 to 1.09 & 0.565 \\
\hline \multicolumn{4}{|l|}{ Employment status } \\
\hline \multicolumn{4}{|l|}{ None (Ref) } \\
\hline $\begin{array}{l}\text { Working before and during } \\
\text { COVID-19 }\end{array}$ & 0.59 & 0.35 to 0.97 & 0.033 \\
\hline $\begin{array}{l}\text { Loss of employment during } \\
\text { COVID-19 }\end{array}$ & 1.08 & 0.78 to 1.38 & 0.090 \\
\hline Higher annual income level & 0.65 & 0.48 to 0.87 & 0.005 \\
\hline Inadequate income & 1.77 & 1.28 to 2.44 & 0.001 \\
\hline \multicolumn{4}{|l|}{ Debt status } \\
\hline \multicolumn{4}{|l|}{ None (Ref) } \\
\hline Existing debt before COVID-19 & 1.48 & 1.08 to 2.03 & 0.015 \\
\hline Incurred debt during COVID-19 & 2.74 & 1.57 to 4.80 & $<0.001$ \\
\hline Affected expenditures & 1.33 & 0.95 to 1.86 & 0.088 \\
\hline Disrupted mobility activities & 1.22 & 0.86 to 1.74 & 0.235 \\
\hline Disrupted socialisation activities & 1.10 & 0.80 to 1.51 & 0.573 \\
\hline Poor self-rated health & 2.01 & 1.27 to 3.17 & 0.003 \\
\hline Physical health difficulties & 1.92 & 1.23 to 2.99 & 0.004 \\
\hline $\begin{array}{l}\text { Dissatisfied with life during } \\
\text { COVID-19 }\end{array}$ & 1.49 & 0.45 to 1.87 & 0.023 \\
\hline Constant & 0.92 & & \\
\hline Pseudo $R^{2}$ & 0.15 & & \\
\hline
\end{tabular}

including worse vision and hearing, among others, and dissatisfaction with their lives were observed among most respondents in the study sample. Anxiety and concern have been observed before with regard to the influenza $\mathrm{A}(\mathrm{H} 1 \mathrm{~N} 1)$ outbreak, during which adults thought about their vulnerabilities to infection among other aspects of a pandemic. ${ }^{26}$ A similar worry and fear has been noted during COVID-19 among adults in Turkey. ${ }^{27}$ Older Thais had concerns about infection, the experience of sheltering in place, and the stress of having less to spend, all of which influenced how they perceived their own health state and life satisfaction.

There are limitations to this study. First, psychological distress is based on respondents' self-reported feelings. The measure does not represent a medical diagnosis of respondents' psychological state. Second, the study is based on a cross-sectional survey; therefore, causation was not established. Observations of the development of individuals' socioeconomic and health states through a longitudinal study would offer advantages, particularly to determine changes before, during and after the COVID-19 pandemic. Despite these limitations, this study provides insights on the vulnerabilities of the older population. A support system would be advantageous during outbreaks. Social protection also has to be strengthened even in times outside of a pandemic situation. This would provide security in the event of circumstances that may result in financial shocks.

\section{CONCLUSION}

The COVID-19 pandemic has been unprecedented for Thailand because of the measures implemented with regard to distancing restrictions. Although the public health policies enacted were necessary from the viewpoint of the government to curb the transmission of the disease, they affected people's social and economic lives, especially those considered vulnerable, such as older adults. This study observed that the precariousness of older adults' financial statuses was associated with the experience of psychological distress. The situation is continuing to evolve, and the impact in the longer term has to be considered.

Acknowledgements This research was made possible by the Ratchadaphisek Somphot Postdoctoral Fund from the Graduate School, Chulalongkorn University. The work was done with support from the Population, Family Dynamics and Social Policy research unit, also at Chulalongkorn University.

Contributors PMMV initiated the study. The survey was carried out by WP. The initial version of the paper was written by PMMV with guidance from WP. Revisions were provided by WP. Both authors approved both the original and revised versions to be published.

Funding The authors have not declared a specific grant for this research from any funding agency in the public, commercial or not-for-profit sectors.

\section{Competing interests None declared.}

Patient and public involvement Patients and/or the public were not involved in the design, or conduct, or reporting, or dissemination plans of this research.

\section{Patient consent for publication Not required.}

Ethics approval The survey was reviewed and approved by the Research Ethics Review Committee of Chulalongkorn University.

Provenance and peer review Not commissioned; externally peer reviewed.

Data availability statement Data are available on reasonable request. The survey and data are available through the College of Population Studies, Chulalongkorn University, Thailand.

Open access This is an open access article distributed in accordance with the Creative Commons Attribution Non Commercial (CC BY-NC 4.0) license, which permits others to distribute, remix, adapt, build upon this work non-commercially, and license their derivative works on different terms, provided the original work is properly cited, appropriate credit is given, any changes made indicated, and the use is non-commercial. See: http://creativecommons.org/licenses/by-nc/4.0/. 
ORCID iD

Paolo Miguel Manalang Vicerra http://orcid.org/0000-0003-3076-7440

\section{REFERENCES}

1 World Health Organization. 2019 novel coronavirus (2019-nCoV) strategic preparedness and response plan for the south-east Asia region. World Health organization regional office for south-east Asia, 2020.

2 Glowacz F, Schmits E. Psychological distress during the COVID-19 lockdown: the young adults most at risk. Psychiatry Res 2020;293:113486.

3 Fontes WHdeA, Gonçalves Júnior J, de Vasconcelos CAC, et al. Impacts of the SARS-CoV-2 pandemic on the mental health of the elderly. Front Psychiatry 2020;11:841.

4 García-Portilla P, de la Fuente Tomás L, Bobes-Bascarán T, et al. Are older adults also at higher psychological risk from COVID-19? Aging Ment Health 2020;17:1-8.

5 Bueno-Notivol J, Gracia-García P, Olaya B, et al. Prevalence of depression during the COVID-19 outbreak: a meta-analysis of community-based studies. Int J Clin Health Psychol 2021;21:100196.

6 Santabárbara J, Lasheras I, Lipnicki DM, et al. Prevalence of anxiety in the COVID-19 pandemic: an updated meta-analysis of communitybased studies. Prog Neuropsychopharmacol Biol Psychiatry 2021;109:110207.

7 Luo Y, Hawkley LC, Waite LJ, et al. Loneliness, health, and mortality in old age: a national longitudinal study. Soc Sci Med 2012;74:907-14.

8 Gupta M, Wahl B, Adhikari B, et al. The need for COVID-19 research in low- and middle-income countries. Glob Heal Res Policy 2020;5:33

9 Cénat JM, Dalexis RD, Guerrier M, et al. Frequency and correlates of anxiety symptoms during the COVID-19 pandemic in low- and middle-income countries: a multinational study. J Psychiatr Res 2021;132:13-17.

10 United Nations. 2019 revision of World population prospects, 2019. Available: https://population.un.org/wpp/ [Accessed 6 Dec 2019].

11 Aekplakorn W, Inthawong R, Kessomboon P, et al. Prevalence and trends of obesity and association with socioeconomic status in Thai adults: National health examination surveys, 1991-2009. J Obes 2014;2014:1-8.

12 Karcharnubarn R, Rees P, Gould M. Healthy life expectancy changes in Thailand, 2002-2007. Health Place 2013;24:1-10.

13 Wattanasaovaluk K, Wattanasaovaluk K. The economic significance of work experience for elderly employment in Thailand. JPSS 2021;29:82-99.
14 Vicerra PMM. Knowledge-Behavior gap on COVID-19 among older people in rural Thailand. Gerontol Geriatr Med 2021;7:233372142199720.

15 Katewongsa P, Widyastari DA, Saonuam P. The effects of the COVID-19 pandemic on the physical activity of the Thai population: Evidence from Thailand's Surveillance on Physical Activity 2020. J Sport Heal Sci 2020:1-8.

16 Goodwin R, Wiwattanapantuwong J, Tuicomepee A, et al. Anxiety and public responses to covid-19: early data from Thailand. $J$ Psychiatr Res 2020;129:118-21.

17 UNFPA Thailand. COVID-19 and Older Persons - Evidence from the Survey in Thailand, 2020. Available: https://thailand.unfpa.org/en/ covid-op [Accessed 12 Feb 2021].

18 Vicerra PMM, Pothisiri W. Projecting health needs of late life adults in Thailand: Cognition-adjusted dependency and role of education. $J$ Public Heal Dev 2020;18:37-57.

19 Kivi M, Hansson I, Bjälkebring P. Up and About: Older Adults' Wellbeing During the COVID-19 Pandemic in a Swedish Longitudinal Study. J Gerontol B Psychol Sci Soc Sci 2021;76:e4-9.

20 Gloede O, Menkhoff L, Waibel H. Shocks, individual risk attitude, and vulnerability to poverty among rural households in Thailand and Vietnam. World Dev 2015;71:54-78.

21 Adhikari R, Soonthorndhada K, Haseen F. Labor force participation in later life: evidence from a cross-sectional study in Thailand. BMC Geriatr 2011;11:1-8.

22 Knodel J. Is intergenerational solidarity really on the decline? cautionary evidence from Thailand. Asian Popul Stud 2014;10:176-94.

23 Fujioka R, Thangphet S. Decent work for older persons in Thailand, 2009.

24 Suwanrada W, Wesumperuma D. Development of the Old-age Allowance System in Thailand: Challenges and Policy Implications. In: Handayani SW, Babajanian B, eds. Providing social security in old age: social pensions in Asia. Asian Development Bank, 2012: 153-67.

25 Schmitt V, Sakunphanit T, Prasitsiriphol O. Social protection assessment based national dialogue: towards a nationally defined social protection floor in Thailand. Bangkok: International Labour Organization, 2013.

26 Bults M, Beaujean DJMA, de Zwart O, et al. Perceived risk, anxiety, and behavioural responses of the general public during the early phase of the influenza A (H1N1) pandemic in the Netherlands: results of three consecutive online surveys. BMC Public Health 2011;11:1-13.

27 Satici B, Gocet-Tekin E, Deniz ME, et al. Adaptation of the fear of COVID-19 scale: its association with psychological distress and life satisfaction in turkey. Int J Ment Health Addict 2020:1-9. 